\title{
LETTER
}

\section{Prevention of acute kidney injury by intravenous sodium bicarbonate: the end of a saga}

Helmut Schiffl

See related research by Tie et al., http://ccforum.com/content/18/5/517

The systematic review and meta-analysis of prospective randomized trials reported by Tie and colleagues [1] in a previous issue of Critical Care provide evidence that intravenous sodium bicarbonate (SBIC) administration does not reduce the incidence of cardiac surgery-associated (CSA) acute kidney injury (AKI) but prolongs the duration of mechanical ventilation and of hospital stay.

The conclusions of the authors are corroborated by a recent comprehensive systematic review [2] demonstrating that the administration of SBIC to patients at risk for CSA-AKI, contrast-induced nephropathy, septic AKI, or pigment nephropathy has no additional benefit compared with saline but adds to in-hospital morbidity and mortality.

The authors do not discuss the mechanisms underlying possible harms of SBIC. In cardiac patients, this type of fluid may precipitate volume overload and acute pulmonary edema. Alkalosis-induced hypoventilation may be associated with myocardial ischemia aggravating decreased cardiac contractility and may cause arrhythmia by inducing hypokalemia $[3,4]$.

The principal intervention with proven efficacy for the prevention of AKI is adequate fluid administration. Definitively, SBIC is not the optimal fluid.

\section{Authors' response \\ Hong-Tao Tie, Qing-Chen Wu and Jing-Yuan Wan}

We appreciate Schiffl's insightful commentary, which encourages us to expand on the mechanisms of SBIC in the prevention of CSA-AKI.

The inefficacy of SBIC was due to the hypothesis that the significant increased power of hydrogen $(\mathrm{PH})$ might not be adequate to prevent CSA-AKI. Nevertheless, the increased $\mathrm{PH}$ and subsequent disruption of homeostasis

Correspondence: h-schiffl@t-online.de

SRH Applied University of Health Sciences, Neue Str. 28-30, D-07548 Gera, Germany

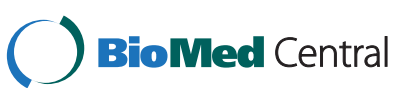

(c) 2014 Schiffl; licensee BioMed Central Ltd. This is an Open Access article distributed under the terms of the Creative Commons Attribution License (http://creativecommons.org/licenses/by/4.0), which permits unrestricted use, distribution, and reproduction in any medium, provided the original work is properly credited. The Creative Commons Public Domain Dedication waiver (http://creativecommons.org/publicdomain/zero/1.0/) applies to the data made available in this article, unless otherwise stated. could cause possible harms. Firstly, arrhythmia and hypoventilation via inducing hypokalemia and alkalosis impair the cardiac function, as indicated by Schiffl. Moreover, hypocapnia by inducing alkalosis could reduce the cerebral blood flow and result in seizures and even coma or death [5]. Secondly, SBIC administration could impair the oxygenation and subsequently exacerbate the ischemia-reperfusion injury by aggravating the ischemia [4]. Thirdly, the induced intracellular alkalinization is associated with increased cell death, cell apoptosis, superoxide formation, pro-inflammatory cytokine release, blood lactate, and ketone bodies [6]. Finally, SBIC could cause decreased arterial blood pressure [7], an emergency situation for patients after cardiac surgery. Therefore, the risks overwhelm the benefits of SBIC for CSA-AKI prevention in patients undergoing cardiac surgery.

However, the hypothesis that SBIC administration may precipitate volume overload and acute pulmonary edema seems irrational because each patient received the same solution (for example, 5\% dextrose) and the same amount of fluid volume in each study. In short, the possible harms of SBIC should not be attributed to volume overload and acute pulmonary edema.

\section{Abbreviations \\ AKI: acute kidney injury; CSA: cardiac surgery-associated; PH: power of hydrogen; SBIC: sodium bicarbonate.}

\section{Competing interests}

The author declares that he has no competing interests.

Published online: 27 November 2014

\footnotetext{
References

. Tie HT, Luo MZ, Luo MJ, Zhang M, Wu QC, Wan JY: Sodium bicarbonate in the prevention of cardiac surgery-associated acute kidney injury: a systematic review and meta-analysis. Crit Care 2014, 18:517.

2. Schiffl $\mathrm{H}$ : Sodium bicarbonate infusion for prevention of acute kidney injury: no evidence for superior benefit, but risk for harm? Int Urol Nephrol 2014, [Epub ahead of print].

3. Bersin RM, Chatterjee K, Arieff Al: Metabolic and hemodynamic consequences of sodium bicarbonate administration in patients with consequences of sodium bicarbonate
} 
4. Anderson LE, Henrich WL: Alkalemia-associated morbidity and mortality in medical and surgical patients. South Med J 1987, 80:729-733.

5. Adrogue HJ: Mixed acid-base disturbances. J Nephrol 2006, 19:S97-S103.

6. Hougardy JM, De Backer D: Sodium bicarbonate to prevent cardiac surgery-associated kidney injury: the end of a dream? Crit Care 2012, 16:186.

7. Haase M, Haase-Fielitz A, Plass M, Kuppe H, Hetzer R, Hannon C, Murray PT, Bailey MJ, Bellomo R, Bagshaw SM: Prophylactic perioperative sodium bicarbonate to prevent acute kidney injury following open heart surgery: a multicenter double-blinded randomized controlled trial. PLOS Med 2013, 10:e1001426.

doi:10.1186/s13054-014-0672-0

Cite this article as: Schiff: Prevention of acute kidney injury by intravenous sodium bicarbonate: the end of a saga. Critical Care 2014 18:672. 